\title{
Rainfall frequency analysis of Nainital District (Uttarakhand)
}

\author{
Mahendra Rai, R.K. Mehta, R.B. Gautam* and K.K. Maurya \\ N.D. University of Agriculture and Technology, Kumarganj, Faizabad (U.P.) \\ *Email: rksh_gautam@yahoo.co.in
}

\begin{abstract}
The rainfall process is non linear, hence having uncertainty in forecasting its pattern. Rainfall data for the year of 1986 to 2010 were used for return period and statistical analysis for Nainital district of Uttarakhand. The return periods from different methods were evaluated and find out to be 25 year maximum and 1 year minimum. There was higher variation in standard deviation where as medium to small variations in coefficient of variation, coefficient of skewness and coefficient of Kurtosis for estimation return period Weibull method was used to be 25 year to 1 year.
\end{abstract}

Keywords: Rainfall, Return period, Distribution, Rainfall frequency.

Paper cited: Rai, M., Mehta, R.K., Guatam, R.B. and Maurya, K.K. (2018). Rainfall frequency analysis of Nainital District (Uttarakhand). South Asian Journal of Food Technology and Environment, 4(2): 748-752.

\section{Introduction}

The design of soil and water conservation structures requires relatively long record of rainfall data. Most of the hydrological events occurring as natural phenomena are observed only once. One of the important problem in hydrology deals with interpretating past record of hydrological events in terms of future probabilities with occurrence. The procedure of estimating frequency of occurrence of a hydrologic event is known as frequency analysis. It is possible to predict design rainfall fairly accurate for certain return period using various probability distributions. Several models have been developed for daily, weekly, monthly and annual rainfall values (Haitiner and Salas, 1988; Agarwal 1988; Ready and Kumar, 1999; Suresh, 2003; Suresh, 2004; Subhas and Das, 2004; Subramanaya, 2005; Ravi et al., 2006; Bhakar et al., 2006 and Jeevarathnam and Jaykumar, 1979). Daily rainfall data are used in hydrological analysis for future planning of drainage System and permanent soil conservation structure design as well as forecasting hydrological future events. On above view rainfall frequency analysis of Nainital district of Uttarakhand were taken in this study. The present study was taken with following objectives-
1. To compute the frequency of rainfall for return period using Weibull formulae, Gamble distribution method and $\log$ pearson type III distribution method.

2. To compute the statistical parameters such as standard deviation, Coefficient of variation, Coefficient of Skewness and Coefficient of Kurtosis.

\section{Materials and Methods}

Nainital is located between $28^{\circ} 43^{\prime}$ North Latitude to $77^{\circ} 31^{\prime}$ East Longitude the sail is lighter. Average annual rainfall is $834 \mathrm{~mm}$. Monthly rainfall data for 15 years (1986-2010) were collected from department of irrigation, district Nainital.

\section{Analysis of rainfall data}

The recurrence interval of event was obtained by the probability method as follow:

The available rainfall data of 25 years were arranged in descending order of magnitude. Probability of occurrence is reciprocal of recurrence interval. 


\section{Weibull formula:}

$\mathrm{P}=\frac{m}{n+1}, \mathrm{~T}=1 / \mathrm{P}$

Where $\mathrm{n}$ is total number of years of record, $\mathrm{m}$ is rank of observed rainfall value after arranging them in descending order of magnitude, $\mathrm{P}$ is probability of occurrence and $\mathrm{T}$ is return period.

\section{Gamble's distribution method:}

formulae

Expected rainfall is evaluated by following $\mathrm{X}_{\mathrm{T}}=\bar{X}-K \delta$

Where, $X_{\mathrm{T}}=$ expected rainfall

$\bar{X}=$ mean of rainfall

$\delta=$ Standard deviation

$\mathrm{K}=\mathrm{X}_{\mathrm{T}}-\mathrm{Y}_{\mathrm{n}}=$ general function of hydraulic analysis

$$
\begin{aligned}
& \mathrm{Y}_{\mathrm{n}}=\ln \ln [T /(T-1)] \\
& \mathrm{Y}_{\mathrm{n}}=0.5268
\end{aligned}
$$

\section{Log pearson type III distribution:}

In this method variate is first transformed logarithmic into form of base 10 and the transformed data analyzed.

If $X$ is the variant of random hydraulic series then series of $Z$ is variant.

$\mathrm{Z}_{\mathrm{T}}=\bar{Z}+\mathrm{K}_{\mathrm{Z}}$

$\mathrm{Z}=$ variant, $\mathrm{Z}_{\mathrm{T}}=$ variant of return period

$\mathrm{K}_{\mathrm{Z}}=$ frequency factor

Apart from using above formulae for probability distribution calculate to find out return period of a particular rainfall the statistical parameters said as standard deviation (S.D.), Coefficient of variation (C.V.), Coefficient of Skewness (C.S.) and Coefficient of Kurtosis (C.K.) were computed. The computed return period by different probability distribution method are shown in Tables 1, 2 and 3. The statistical parameters like S.D., C.V., C.S. and C.K. are shown in Table 4.

\section{Results and Discussion}

During study different probability distribution methods such as Weibull's method, Gamble method and Log-pearson type III distribution method were used to determine the return period. The accuracy of result was computed by utilizing various parameters. As per Gamble method the maximum mean rainfall vary from $178.60 \mathrm{~mm}$ to $652.3 \mathrm{~mm}$ which return period was found to be 25 and 1 years (Table 1). It means frequency of occurrence is very low. The return period by Weibull's method is 26 and 1 year.

A high value of rainfall expected to occur once in 25 year where as lowest rainfall expected to occur once in a 1 year period.

\section{Computation of Statistical Parameters:}

a. Standard Deviation (SD): There is large variation in the value of maximum and minimum of standard deviation (Table 4). The average value of standard of deviations is computed as 115.17 for 25 years rainfall data.

b. Coefficient of Variation (CV): There is small variation in maximum and minimum value of coefficient of variation $(\mathrm{CV})$ during 25 years (Table 4 ). The average value of CV is 1.104 for 25 years rainfall data.

c. Coefficient of Skewness (CS): The average value of $\mathrm{CS}$ is 0.733 for 25 years rainfall below as there is small variation in maximum and minimum value of CS during 25 years (Table 4).

d. Coefficient of Kurtosis (CK): The average value of Coefficient of Kurtosis was find to be 1.83 for 25 years data even through the variation is small (Table 4).

Table 1: Calculation of return period $T_{p}$ for observed data of District Nainital by Gumble Method:

\begin{tabular}{|c|c|c|}
\hline Order & Rainfall $(\mathbf{m m})$ & Return Period (year) \\
\hline 1 & 652.3 & 25 \\
\hline 2 & 575.5 & 12.5 \\
\hline 3 & 524.1 & 8.33 \\
\hline 4 & 507.8 & 6.25 \\
\hline 5 & 477 & 5 \\
\hline 6 & 464.2 & 4.16 \\
\hline 7 & 456.8 & 3.57 \\
\hline 8 & 430.8 & 3.13 \\
\hline 9 & 413.4 & 3.57 \\
\hline
\end{tabular}




\begin{tabular}{|c|c|c|}
\hline 10 & 409 & 1.47 \\
\hline 11 & 347.2 & 2.27 \\
\hline 12 & 340.1 & 2.08 \\
\hline 13 & 331.6 & 8.33 \\
\hline 14 & 330 & 1.78 \\
\hline 15 & 330 & 1.67 \\
\hline 16 & 324.6 & 1.56 \\
\hline 17 & 320.4 & 1.47 \\
\hline 18 & 312.2 & 1.38 \\
\hline 19 & 283 & 1.32 \\
\hline 20 & 260.9 & 1.25 \\
\hline 21 & 256.8 & 1.19 \\
\hline 22 & 233.5 & 1.14 \\
\hline 23 & 229.8 & 1.09 \\
\hline 24 & 210.2 & 1.04 \\
\hline 25 & 178.6 & 1 \\
\hline
\end{tabular}

Table 2 Calculation of the return period by Weibull Formula $(\mathrm{N}=25$ years)

\begin{tabular}{|c|c|c|c|}
\hline Order & Rainfall (mm) & Probability (P) & Return Period (year) \\
\hline 1 & 163 & 0.038 & 26.3 \\
\hline 2 & 153 & 0.077 & 12.9 \\
\hline 3 & 134 & 0.115 & 8.69 \\
\hline 4 & 130 & 0.154 & 6.49 \\
\hline 5 & 129 & 0.192 & 5.21 \\
\hline 6 & 112 & 0.23 & 4.35 \\
\hline 7 & 112 & 0.269 & 3.72 \\
\hline 8 & 109 & 0.308 & 3.25 \\
\hline 9 & 108 & 0.346 & 2.89 \\
\hline 10 & 106 & 0.385 & 2.59 \\
\hline 11 & 105 & 0.423 & 2.36 \\
\hline 12 & 102 & 0.462 & 2.16 \\
\hline 13 & 102 & 0.5 & 2 \\
\hline 14 & 100 & 0.538 & 1.86 \\
\hline 15 & 97 & 0.577 & 1.73 \\
\hline 16 & 96 & 0.615 & 1.63 \\
\hline 17 & 93 & 0.654 & 1.53 \\
\hline 18 & 92 & 0.692 & 1.45 \\
\hline 19 & 87 & 0.731 & 1.37 \\
\hline 20 & 85 & 0.769 & 1.3 \\
\hline 21 & 77 & 0.81 & 1.23 \\
\hline 22 & 77 & 0.846 & 1.18 \\
\hline 23 & 70 & 0.885 & 1.13 \\
\hline 24 & 68 & 0.923 & 1.08 \\
\hline 25 & 59 & 0.96 & 1.04 \\
\hline
\end{tabular}


Mahendra Rai, R.K. Mehta, R.B. Gautam and K.K. Maurya

Table 3 Computation of the return period by using Log Pearson-III method:

\begin{tabular}{|c|c|c|c|}
\hline Order & Year & Maximum Rainfall & Return Period \\
\hline 1 & 1986 & 464.2 & 2.67 \\
\hline 2 & 1987 & 477 & 2.68 \\
\hline 3 & 1988 & 229.8 & 2.36 \\
\hline 4 & 1989 & 575.5 & 2.76 \\
\hline 5 & 1990 & 283 & 2.45 \\
\hline 6 & 1991 & 430.8 & 2.63 \\
\hline 7 & 1992 & 413.4 & 2.62 \\
\hline 8 & 1993 & 330 & 2.52 \\
\hline 9 & 1994 & 256.8 & 2.41 \\
\hline 10 & 1995 & 331.6 & 2.52 \\
\hline 11 & 1996 & 524.1 & 2.72 \\
\hline 12 & 1997 & 324.6 & 2.51 \\
\hline 13 & 1998 & 340.1 & 2.53 \\
\hline 14 & 1999 & 178.6 & 2.25 \\
\hline 15 & 2000 & 652.3 & 2.81 \\
\hline 16 & 2001 & 507.8 & 2.71 \\
\hline 17 & 2002 & 409 & 2.61 \\
\hline 18 & 2003 & 330 & 2.52 \\
\hline 19 & 2004 & 210.2 & 2.32 \\
\hline 20 & 2005 & 320.4 & 2.51 \\
\hline 21 & 2006 & 456.8 & 2.66 \\
\hline 22 & 2007 & 233.5 & 2.37 \\
\hline 23 & 2008 & 347.2 & 2.54 \\
\hline 24 & 2009 & 260.9 & 2.42 \\
\hline 25 & 2010 & 312.2 & 2.49 \\
\hline & & & \\
\hline
\end{tabular}

Table 4: Statistical parameter of monthly rainfall $(\mathrm{mm})$ data for different years of district Nainital

\begin{tabular}{|c|c|c|c|c|c|c|c|}
\hline Year & Max & Min & Average & S.D. & C.V. & C.S. & C.K. \\
\hline 1986 & 464.2 & 1.8 & 112.5 & 152.4 & 1.35 & 0.67 & 1.63 \\
\hline 1987 & 477 & 2.5 & 105.8 & 147.6 & 1.39 & 0.69 & 1.85 \\
\hline 1988 & 229.8 & 7.4 & 85.9 & 78.6 & 0.91 & 0.324 & 0.86 \\
\hline 1989 & 575.5 & 2.4 & 129.16 & 175.7 & 1.36 & 0.739 & 1.89 \\
\hline 1990 & 283 & 1.6 & 87.6 & 84.6 & 0.97 & 0.563 & 1.44 \\
\hline 1991 & 430.8 & 0.8 & 153.2 & 148.5 & 0.97 & 0.309 & 0.85 \\
\hline 1992 & 413.4 & 4 & 112.7 & 149.5 & 1.32 & 0.554 & 1.24 \\
\hline 1993 & 330 & 45 & 106.8 & 94.3 & 0.88 & 0.872 & 1.99 \\
\hline 1994 & 256.8 & 6.2 & 70.6 & 90.3 & 1.27 & 0.608 & 1.32 \\
\hline 1995 & 331.6 & 0.2 & 109.8 & 110.2 & 1 & 0.471 & 1.76 \\
\hline 1996 & 524.1 & 2 & 102.2 & 144.6 & 1.4 & 1.02 & 3.06 \\
\hline 1997 & 324.6 & 7.4 & 96.4 & 94.5 & 0.98 & 0.541 & 1.48 \\
\hline 1998 & 340.1 & 12.4 & 100.3 & 117.5 & 1.17 & 0.437 & 1.08 \\
\hline 1999 & 178.6 & 0.4 & 68.15 & 62.4 & 0.92 & 0.478 & 1.29 \\
\hline 2000 & 652.3 & 1.6 & 163.8 & 21.6 & 1.32 & 0.519 & 1.29 \\
\hline 2001 & 507.8 & 0.2 & 102.3 & 136.8 & 1.34 & 1.03 & 3.26 \\
\hline
\end{tabular}


Rainfall frequency analysis of Nainital District (Uttarakhand)

\begin{tabular}{|l|c|c|c|c|c|c|c|}
\hline 2002 & 409 & 7 & 93.7 & 113.3 & 1.21 & 1.98 & 2.58 \\
\hline 2003 & 330 & 30.4 & 134.6 & 134.3 & 0.99 & 0.83 & 2.43 \\
\hline 2004 & 210.2 & 2.1 & 77 & 82.4 & 1.07 & 0.362 & 0.78 \\
\hline 2005 & 320.4 & 2.9 & 130.8 & 118.5 & 0.91 & 0.142 & 0.79 \\
\hline 2006 & 456.8 & 3.9 & 97.3 & 124.3 & 1.28 & 0.964 & 2.96 \\
\hline 2007 & 233.5 & 2.4 & 59.8 & 79.2 & 1.32 & 0.704 & 1.61 \\
\hline 2008 & 347.2 & 10.4 & 92.2 & 105.1 & 1.14 & 0.772 & 1.87 \\
\hline 2009 & 260.9 & 2.2 & 85.1 & 21.6 & 0.25 & 2.18 & 4.98 \\
\hline 2010 & 312.2 & 14.9 & 108.8 & 97.1 & 0.89 & 0.588 & 1.48 \\
\hline Avg. & & & & $\mathbf{1 1 5 . 7}$ & $\mathbf{1 . 1 0 4}$ & $\mathbf{0 . 7 3 3}$ & $\mathbf{1 . 8 3}$ \\
\hline
\end{tabular}

\section{Conclusion}

On the basis of study the following conclusion were drawn:

- Rainfall frequency analysis for 25 years rainfall data of Nainital district suggest that larger storm of rainfall will occure once in 25 years the permount soil and water conservation structure my design to keep in mind the maximum value of rainfall occurred during 25 years.

- The statistical data showing large variation in standard deviation (S.D.) indicates that the data of rainfall are spread out over a large range of value range in true. Small variation in maximum and minimum value of $\mathrm{CV}, \mathrm{CS}$, $\mathrm{CK}$ was observed which validate the data of rainfall for 25 years. The calculated return period by using Weibull method, Gambel method and Log-pearson type III method will help in selecting the best for transformation for estimation of expected rainfall at different period and can be utilize for planning of drainage \& permanent structure project in Nainital district.

\section{References}

1. Agarwal, A. (1988). Stochastic model or monthly rainfall for Nainital Tarai. Journal of Agricultural Engineering, 25:20-31.

2. Bhakar, S.R., Bansal, A.K., Chhajed, N. and Purohit, R.C. (2006). Frequency analysis of consecutive days maximum rainfall at
Banswana Rajasthan India. APRN Journal of Engineering and Applied Science, 1(3): 64-67.

3. Haitiner, J.P. and Salas, J.B. (1988). Development and Festing of multivariate seasonal ARMA $(1 ; 1)$ model. Journal of Hydrology, 223 (3-4):148-163.

4. Jeevarathnam, K. and Jaykumar, M. (1979). Probability analysis of maximum daily rainfall for Ootacamund. Indian Journal of Soil Conservation, 7(1): 10-16.

5. Reddy, K.M. and Kumar, D. (1999). Time series analysis of monthly rainfall for bino watershed of Ramganga river. Journal of Agricultural Engineering, 36(4):19-29.

6. Rabv, B.R., Mishra, P., Mazumdar, A. and Roy, D. (2006). Probability analysis of rainfall of Bankura for design of soil and water conservation structures. Journal of Agricultural Engineering, 43(1): 22-29.

7. Subhash, N. and Das, P.K. (2004). Rainfall characteristics and probability analysis for crop planning under rice wheat system in sub hunid (dry) climate. Indian Journal of Soil Conservation, 32(2): 124-128.

8. Subramanaya, K. (2005). Engineering Hydrology. Tata Mc-Graw Hill, New Delhi.

9. Suresh, R. (2003). Probability models for predicting annual maximum daily rainfall for pusa farm (Bihar). Indian Journal of Soil Conservation, 31(1):84-85.

10. Suresh, R. (2004). Soil and Water Conservation Engineering (4/e). Standard Publication distribution, Delhi (2): 36-37.

$\begin{array}{ll}\text { Received } & \text { : July., 2018 } \\ \text { Revised } & \text { : Nov., 2018 } \\ \text { Published } & \text { : Dec., 2018 }\end{array}$

